\title{
Proposta de um Modelo para Determinação do Custo de Capital Baseado em Análise Hierárquica
}

\author{
Diana Macêdo Matos \\ Heber José de Moura
}

\begin{abstract}
Resumo
O presente trabalho consiste numa aplicação da abordagem multicritério no cálculo da taxa de desconto, tendo em vista as limitações das técnicas existentes quando o objeto de estudo é uma empresa de capital fechado. Pretende-se aqui expor uma metodologia, de caráter interdisciplinar, baseada na Teoria da Decisão, especificamente por meio da aplicação do Método de Análise Hierárquica (AHP) na estimativa do custo de capital próprio. A partir do método AHP foi possível identificar e incorporar relevantes fatores de risco para o empreendimento, incluindo simultaneamente variáveis qualitativas e quantitativas no processo. O modelo permitiu ainda apontar, hierarquicamente, como os diversos fatores estão contribuindo na formação do prêmio de risco da empresa, fato este não verificado em outras técnicas de análise. Finalmente, procurou-se ilustrar a aplicação do modelo proposto, calculando-se, para tanto, o custo de capital próprio de uma indústria de médio porte e de capital fechado do Estado do Ceará.
\end{abstract}

Palavras-chaves: custo de capital próprio; método de análise hierárquica; teoria de decisão multicritério; empresas de capital fechado.

\begin{abstract}
This paper consists of a proposal to evaluate closely held companies, by the use of MultipleCriteria Decision Method in the calculation of the discount rate. It is intended here to expose an interdisciplinary methodology, based on the Theory of Decision, specifically through the application of the Analytical Hierarchy Process (AHP) in the estimate of the cost of equity. With AHP was possible to identify and to incorporate qualitative risk factors in the model, including qualitative and quantitative variables simultaneously in the process. Finally, this research tried to illustrate through a case study the application of the proposed methodology, by the valuation of a median closely held industry from the state of Ceará.
\end{abstract}

Key words: cost of capital; closely held business; multiple-criteria decision analysis; analytical hierarchy process (AHP). 


\section{INTRODUÇÃO}

A partir dos anos 50, com o desenvolvimento da moderna Teoria da Carteira, os modelos voltados à aferição da relação entre risco e retorno dos investimentos foram-se aperfeiçoando, mediante abordagens mais quantitativas e específicas em suas projeções. O debate ainda continua apresentando deficiências e limitações, tanto em nível teórico como prático, especialmente tratando-se da utilização de modelo adequado à estimativa do custo de capital.

As questões de como o risco é medido e recompensado são fundamentais em cada decisão de investimento, desde a alocação de ativos até a sua avaliação. Assim, estimar o custo de capital é uma das tarefas mais relevantes no processo de avaliação de empresas. O desafio maior é o de quantificar o efeito do risco no custo de capital próprio para aquelas empresas não cotadas em bolsa. Os diversos modelos encontrados na literatura financeira, até pouco tempo, orientavam-se quase exclusivamente a empresas de capital aberto - principalmente em virtude da facilidade de obtenção de informações - baseando seus pressupostos na Teoria Moderna de Finanças, especificamente no Modelo de Precificação dos Ativos Financeiros (CAPM).

Mesmo considerando os métodos mais atuais, aplicados a empresas fechadas, como, por exemplo, o build up, proposto por Pratt et al. (1998), ou outras abordagens mais simples desenvolvidas por Schilt (1992) e Martelanc (1998), a determinação da taxa de desconto para companhias que não operam em bolsa é assunto que continua necessitando de muitas contribuições, haja vista as seguintes questões:

- no caso brasileiro, as pesquisas relacionadas à determinação do prêmio pelo tamanho (size effect) até o presente não estão perfeitamente consolidadas, como atestam os estudos realizados por Bruni (1999), Costa Jr. e O’Hanlon (apud Costa Jr., Leal e Lemgruber, 2000) e Rodrigues (2000);

- a medição do risco inerente a uma empresa específica é processo que envolve subjetividade, a despeito das contribuições já realizadas sobre o assunto.

Obviamente há limitações, seja qual for o procedimento utilizado para o propósito da avaliação de empresas, principalmente porque se trata de estimar o risco do capital próprio, sendo ele composto e influenciado tanto por variáveis qualitativas como quantitativas. As diversas metodologias até agora não conseguem contemplar integralmente as diferentes dimensões do risco, subestimando, às vezes, aspectos subjetivos importantes a que tais empresas estão sujeitas. 
Diante deste contexto, procura-se contribuir para a questão, apresentando uma alternativa para cálculo do custo de capital próprio, a partir dos pressupostos da Teoria da Decisão Multicritério, especificamente por meio do Método de Análise Hierárquica (AHP).

Pretende-se com isto definir um modelo prescritivo que não se restrinja aos aspectos econômico-financeiros do negócio, mas que reflita o risco da empresa sob perspectiva global. Assim, procurou-se incorporar mais explicitamente os fatores intangíveis na análise do risco, pois não se trata apenas de observar índices e percentuais, mas, sobretudo, de estabelecer critérios que levem em conta, por exemplo, questões como a responsabilidade social e o capital intelectual.

\section{O Custo de Capital de Empresas de Capital Fechado}

Para Mascareñas (2000) há quatro fatores que determinam o custo de capital: as condições econômicas, as condições de mercado, as condições financeiras e operacionais, e a quantidade de financiamento para realizar novos investimentos. Estes fatores, quando analisados conjuntamente, vão compor o risco total de uma empresa. O risco total, por sua vez, pode ser visto sob duas perspectivas: o risco sistemático, o qual se refere à incerteza dos retornos esperados causados pelas oscilações do mercado como um todo, e o risco não sistemático, resultante das características da própria empresa, do setor ou do tipo de investimento.

Sob a ótica da Teoria da Carteira, o risco não sistemático pode ser reduzido mediante da diversificação, pois deriva do fato de muitos dos perigos a que uma empresa isolada está sujeita lhe serem específicos, como a ameaça dos concorrentes mais próximos. Já o risco de mercado não se pode evitar por mais que se diversifiquem os investimentos. No entanto, Breadley e Myers (1998), além de outros estudiosos (Edward, 1992; Howitt, 1993; Swad, 1994; Pratt et al., 2000; Reilly e Schweihs, 2000), comentam que a análise do risco não sistemático é muito importante, quando se trata de avaliar uma só empresa.

Damodaran (2002) acredita que o proprietário (ou acionista) de uma empresa de capital fechado concentra a maior parte de sua riqueza no seu próprio negócio e assim ele se preocupa com o risco total da atividade e não somente com o risco de mercado. Além disso, para o referido autor, está implícito no uso do beta, a premissa de que o investidor é possuidor de carteira diversificada. Daí, não sendo este o caso, sugere duas maneiras de estimar o custo do patrimônio de uma empresa fechada, pela ótica do CAPM: 
- acrescentar um ágio ao custo de capital próprio para refletir o maior risco criado pela incapacidade de diversificação do proprietário/investidor;

- ajustar o beta para que reflita o risco total e não apenas o de mercado.

Ademais, Cotner e Fletcher (1999) afirmam que proprietários e investidores de pequenos negócios não consideram suas empresas como parte de carteira diversificada, mas precisamente como projeto de capital.

\section{O Risco Específico da Empresa}

O risco não sistemático, função das peculiaridades de cada empreendimento, envolve aspectos qualitativos e quantitativos relacionados aos seguintes elementos: habilidades e estilos gerenciais, relação entre trabalho e administração, sucesso ou fracasso dos programas de marketing, porte da companhia, diversidade de produtos e clientes, dependência de uma pessoa-chave ou de fornecedores, e ambiente altamente competitivo.

Martelanc (1998) aponta outros fatores de risco tais como os seguintes: vendas instáveis, ramo difícil, predominância de práticas desleais ou ilegais no setor, dependência excessiva das habilidades individuais do antigo proprietário ou de algum empregado importante e dificuldade de sair do ramo.

A forma como a empresa vê o custo de capital depende de seu ramo de negócios, das condições financeiras e do estágio do ciclo de vida. Ele é, pois, um conceito dinâmico afetado por uma variedade de fatores econômicos e empresariais.

Portanto o impacto no custo de capital próprio do risco não sistemático incorpora um tipo de análise subjetiva, carente de evidências empírico-científicas mais consistentes, de acordo com Pratt et al. (2000). Segundo os referidos autores, não há fórmula específica para mensurar quantitativamente o número exato do prêmio de risco específico na taxa de desconto. Neste aspecto, eles argumentam que o bom senso e a experiência do avaliador devem ser levados em consideração.

\section{O Efeito do Tamanho (Size Effect)}

Um dos pressupostos na área financeira tem sido que os retornos esperados sobre as ações são determinados por seu nível correspondente de risco sistemático, ou o fator beta. Por mais de 30 anos foram encontradas fortes evidências empíricas de uma relação positiva e linear entre retorno e risco não diversificável, visualizada pela Linha de Mercado de Títulos (SML). A determinação do retorno associado a 
este tipo de risco se dá por intermédio do modelo denominado CAPM, o qual já é bastante conhecido e detalhadamente discutido em toda a literatura moderna de finanças. O CAPM é plausível e largamente usado, mas está longe de ser perfeito.

A partir dos anos 80, um número crescente de estudos (Banz, 1981; Reinganum, 1981; Fama e French, 1992) documentou a presença de padrões persistentes nos retornos das ações de empresas pequenas, para os quais o CAPM não explicava satisfatoriamente. Assim, nos Estados Unidos e em outros países, pequenas empresas têm tido melhores desempenhos do que as grandes firmas, quando observados por longo período de tempo.

Entre os estudos que apóiam o pressuposto de que companhias menores são mais arriscadas e, conseqüentemente, têm maior custo de capital, destacam-se aqueles desenvolvidos recentemente por Grabowski e King (1996, 1999) da PricewarterhouseCoopers - PwC e Ibbotson Associates (1998). A propósito, Pratt (1998), analisando os resultados das pesquisas supracitadas, observou crescimento marginal muito maior no decil correspondente às menores empresas. Para ele este é um dado relevante, no caso de avaliação de companhias fechadas de pequeno e médio porte, já que se trata do segmento em que está contida a maior parte das empresas desta natureza.

Além disso, Pratt (1998) acredita que os trabalhos de Ibbotson Associates e PwC, além de compatíveis, apresentam fundamentos teóricos bastante consistentes, dando credibilidade e suporte suficientes para incluir, em alguns casos, um prêmio de risco adicional pelo tamanho (Rs) na tradicional fórmula do CAPM, mesmo que isso signifique violação técnica do modelo. Vale ressaltar que tal procedimento é compartilhado por outros pesquisadores (Howitt, 1993; Lippitt e Mastracchio, 1995; Ibbotson, Kaplan e Peterson, 1997; Annin e Falaschetti, 1998; West e Jones, 1999; Reilly e Schweihs, 2000) e praticantes norte-americanos na avaliação de pequenas empresas.

Neste aspecto, a constatação do efeito do tamanho da firma torna-se mais uma variável significante na estimativa do custo de capital próprio, ao utilizar a abordagem por fluxo de caixa descontado no processo de avaliação de empresas.

Diante o exposto, não há dúvidas em relação à inclusão do prêmio adicional pelo tamanho na atual fórmula do CAPM; mas quantificar exatamente o impacto do risco não sistemático no custo do capital próprio ainda requer uma base teórica mais consistente. De qualquer maneira, para os referidos estudiosos, o estado da arte deverá incluir os seguintes elementos no cálculo do custo de capital próprio:

- um prêmio básico sobre a taxa livre de risco; 
. um ou mais coeficientes que irão modificar o prêmio pelo risco baseado em dados do setor ou mercado;

. um elemento que incorpore o efeito do tamanho da empresa (size premium);

- um ajuste final baseado no risco específico da empresa (investment specific risk) não incluído nos três elementos acima.

Assim, a fórmula proposta por Pratt, Reilly e Schweihs (2000) é a seguinte:

$$
\mathbf{E}(\mathbf{R i})=\mathbf{R f}+\boldsymbol{\beta}(\mathbf{R P m})+\mathbf{R P s}+\mathbf{R p u}
$$

onde: $\mathrm{E}(\mathrm{Ri})=$ Taxa esperada de retorno; $\mathrm{Rf}=$ Taxa livre de risco; $\beta=$ Beta; RPm = Prêmio de risco de mercado; RPs = Prêmio de risco pelo pequeno porte (risk premium for small size); Rpu = Prêmio de risco específico da empresa (unsistematic risk).

O cálculo do custo de capital próprio pelo método build-up, expresso anteriormente, considera que as médias e pequenas empresas de capital fechado possuem características similares às menores companhias de capital aberto (menor valor de mercado) apresentadas nos estudos de Ibbotson Associates e PwC. Este é o pressuposto que está sendo utilizado por praticantes norte-americanos na determinação da taxa de desconto de empresas não cotadas em bolsa.

Outra opção para determinar a taxa de desconto do patrimônio líquido, é por meio da aplicação do método escalar de prêmio de risco desenvolvido por Schilt (1982). Baseado em seus estudos empíricos, ele classificou as empresas em cinco categorias distintas, atribuindo um prêmio de risco específico, tendo em vista as suas características, conforme se demonstra no quadro a seguir.

\section{Quadro 1: Prêmio de Risco Proposto por Schilt}

\begin{tabular}{c|l|c}
\hline Categoria & \multicolumn{1}{|c}{ Descrição da Empresa } & Prêmio de Risco \\
\hline 1 & $\begin{array}{l}\text { Empresa já estabelecida no mercado com forte posição, boa } \\
\text { administração, nível ótimo de financiamento, passado estável de } \\
\text { lucros, perspectiva otimista de resultados futuros. }\end{array}$ & $6-10 \%$ \\
\hline 2 & $\begin{array}{l}\text { Empresa já estabelecida em ambiente mais competitivo, bem } \\
\text { financiada, boa administração, passado estável de lucros, mas os } \\
\text { resultados futuros são incertos. }\end{array}$ & $11-15 \%$ \\
\hline 3 & $\begin{array}{l}\text { Empresa instalada em mercado altamente competitivo, pouco } \\
\text { capital investido, administração fraca, apesar de boa história de } \\
\text { lucros passados. }\end{array}$ & $16-20 \%$ \\
\hline 4 & $\begin{array}{l}\text { Pequena empresa que depende das habilidades gerenciais de uma } \\
\text { ou duas pessoas, ou empresa de grande porte de natureza cíclica } \\
\text { em seus negócios. Nos dois casos, os resultados positivos futuros } \\
\text { são incertos. }\end{array}$ & $21-25 \%$ \\
\hline 5 & $\begin{array}{l}\text { Pequena empresa, dependente de um único proprietário, com } \\
\text { lucros bastante incertos. }\end{array}$ & $26-30 \%$ \\
\hline
\end{tabular}

Fonte: Schilt (1982). 
Nesta proposta, este prêmio é adicionado à taxa livre de risco na determinação do custo de capital próprio. No entanto Hamilton (2001) acredita que este método tem a vantagem de ser simples e é, de alguma forma, razoável; contudo seu ponto fraco refere-se ao caráter subjetivo da escala adotada, não identificando o prêmio de risco para cada possível fator. Para Tuller (1994) ele é suficiente para atender aos requisitos necessários ao processo de avaliação de pequenas empresas e companhias de capital fechado; mas, na opinião de Manning (2000), ele serve apenas como guia em casos mais simples e gerais, necessitando de suporte teórico mais profundo.

Martelanc (1998) acredita que riscos significativamente acima da média exigem desvalorização da empresa, propondo uma técnica similar à de Schilt (1982), por meio de quatro categorias de risco apresentadas a seguir.

\section{Quadro 2: Proposta de Martelanc}

\begin{tabular}{l|l|l}
\hline NíVEL DE RISCO & AJUSTE EM CIMA DO VPL & \multicolumn{1}{c}{ CARACTERÍSTICAS DA EMPRESA } \\
\hline Muito alto & Reduções de até 50\% & $\begin{array}{l}\text { Estas empresas tiveram avaliações fortemente } \\
\text { negativas em vários itens* de risco ou foram } \\
\text { negativas em algum item individual. }\end{array}$ \\
\hline Alto & Reduções de até 25\% & $\begin{array}{l}\text { Estas empresas têm riscos elevados em pelo } \\
\text { menos um dos dois itens. }\end{array}$ \\
\hline Normal & Sem alteração & $\begin{array}{l}\text { Não há forte indicação de que o risco seja } \\
\text { extremado em qualquer direção. }\end{array}$ \\
\hline Muito baixo & $\begin{array}{l}\text { Não há evidência de risco em todos os itens } \\
\text { analisados. }\end{array}$ \\
\hline
\end{tabular}

Fonte: Martelanc (1998).

Nota: *Estes itens, citados anteriormente, são: vendas instáveis, ramo difícil, predominância de práticas desleais ou ilegais no setor, dependência excessiva das habilidades individuais do antigo proprietário ou de algum empregado importante, dificuldade de sair do ramo, entre outros.

\section{O Método de Análise Hierárquica}

Dentro da abordagem multicritério, o Método de Análise Hierárquica (AHP) consiste em uma ferramenta que, segundo Goodwin e Wright (2000), poderá ser utilizada em situações que envolvam múltiplos objetivos e resultados. O método AHP tem sido empregado para situações de definição de prioridades, avaliação de custos e benefícios, alocação de recursos, medida de desempenho, decisões estratégicas etc, como atestam Casarotto e Kopittike (2000) e Shimizu (2001).

O método foi desenvolvido por Saaty (1991) na década de 70 e baseia-se em 
três princípios: decomposição, julgamentos comparativos e síntese das prioridades. Os critérios podem ser qualitativos ou quantitativos, não havendo necessidade de escala numérica, pois as comparações são feitas de forma relativa entre as alternativas.

Assim, para utilizar o AHP, genericamente, são necessários os procedimentos a seguir.

\section{. Estruturar os níveis de decisão hierárquica}

Esta etapa é similar à construção de uma árvore de decisão: no topo, situa-se o objetivo maior (geral) e, logo abaixo, localizam-se os critérios associados ao problema de decisão. Estes, por sua vez, devem ser quebrados mais detalhadamente em vários outros níveis (subcritérios), de acordo com a complexidade do problema. Finalmente, as alternativas são adicionadas na hierarquia, abaixo do último nível de critérios.

. Fazer a comparação paritária dos critérios com as alternativas

A seguir, cada critério e/ou subcritério é comparado aos pares, em forma de matriz. Saaty (1991) recomenda que o processo de comparar aos pares deve ser implementado utilizando perguntas verbais. A resposta deverá ser dada seguindo a escala de valores, isto é, os julgamentos comparativos entre as alternativas para dado critério são feitos em escala, como expresso no quadro a seguir.

\section{Quadro 3: Escala de Valores para Comparações Paritárias}

\begin{tabular}{|c|c|}
\hline $\begin{array}{c}\text { Intensidade de } \\
\text { Importância }\end{array}$ & $\begin{array}{c}\text { Frações utilizadas } \\
\text { no modelo }\end{array}$ \\
\hline Mesma importância & $1: 1$ \\
\hline Um pouco mais importante & $3: 1$ \\
\hline Consideravelmente mais importante & $5: 1$ \\
\hline Muito mais importante & $7: 1$ \\
\hline Extremamente mais importante & $9: 1$ \\
\hline Posições intermediárias & $2,4,6,8$. \\
\hline
\end{tabular}

Fonte: Saaty (1991).

Portanto, de acordo com este método, as respostas são convertidas em números, dentro de uma matriz, tendo em vista o grau de importância e prioridade que assumem, podendo variar de 1 a 9, como especificados no quadro anterior.

- Obter os pesos e checar a consistência da matriz

Os pesos são utilizados para verificar a importância relativa de cada critério. 
Este processo é denominado de normalização da matriz, devendo ser seguido pela determinação do índice de consistência da matriz, a fim de garantir os resultados das comparações paritárias.

\section{. Associar os pesos (prioridades relativas) à decisão final}

A escolha da decisão final deverá basear-se naquela alternativa que obtenha o maior escore (peso percentual). Este cálculo é efetuado pela multiplicação dos pesos de cada critério relacionado à alternativa indicada.

\section{Metodologia Proposta}

Neste ponto é apresentada a aplicação do AHP na determinação do custo de capital próprio da empresa. O procedimento permitiu identificar e incorporar fatores relevantes de risco para a empresa, incluindo, simultaneamente, variáveis quantitativas e qualitativas, o que possibilitou superar as dificuldades inerentes ao processo. A técnica consistiu em determinar um prêmio a ser somado a uma taxa livre de risco. Para isto, cinco passos foram necessários.

\section{. Definir as alternativas}

Consistiu em estabelecer um intervalo de prêmio de risco que, de acordo com o modelo, são as alternativas. Para o presente propósito, o prêmio de risco foi classificado em cinco categorias em intervalo que variou entre $6 \%$ (risco muito baixo) e $30 \%$ (muito alto).

\section{. Estabelecer os critérios (ou fatores) de decisão}

O segundo passo no processo foi determinar quais os principais fatores causadores de impacto no risco do negócio, denominados de critérios dentro do modelo AHP. Os fatores (e subfatores) escolhidos para análise foram estabelecidos a partir das características da empresa, baseando-se nos estudos realizados por Schilt (1992), Martelanc (1998), Cotner e Fletcher (1999), e outros, tendo havido até mesmo adaptações, a partir do conhecimento de modelos de avaliação de risco utilizados por instituições financeiras. Assim, os fatores propostos encontram-se listados abaixo.

Fatores Sistemáticos: referem-se àquelas variáveis associadas ao risco sistemático que afetam as empresas como um todo. Os subfatores (ou subcritérios) considerados mais relevantes nesta categoria, foram as condições políticoeconômicas, a taxa de crescimento setorial e os incentivos governamentais. 
Fatores Operacionais: o prêmio de risco também é função das atividades operacionais da empresa. Talvez o mais importante fator relacionado ao risco operacional corresponda aos custos operacionais, em razão da alavancagem. De fato, se estes são altos, bastam as vendas caírem um pouco para que os lucros operacionais despenquem. Logo, quanto mais altos os custos fixos, mais arriscada será a empresa. Por conseqüência disto, os subfatores correspondentes ao seu risco são: condições dos equipamentos, tecnologia empregada, bem como da capacidade produtiva e da qualidade da produção.

Fatores Financeiros: esta dimensão abrange principalmente os aspectos quantitativos relacionados à análise das demonstrações contábeis mediante a observância de alguns índices financeiros. Entre os subfatores examinados, consideraram-se aqueles associados ao endividamento, liquidez e retorno do investimento. A capacidade de pagamento e a variação das vendas e lucros foram outros aspectos abordados para compor o modelo.

Fatores Estratégicos: neste aspecto, ressaltaram-se os fatores associados à posição estratégica da empresa e seu impacto no risco da organização. Assim, foram levados em consideração os subfatores relacionados à participação da empresa no mercado e às principais forças competitivas de Porter (1993).

Fatores de Recursos Humanos (R.H.): relacionam-se praticamente ao posicionamento da empresa em face da sua política de R.H. Primeiramente foram observados os investimentos realizados nesta área, como, por exemplo, os gastos com treinamento, educação, saúde, cesta básica, assistência médica etc. A seguir, examinou-se o nível de profissionalização da mão-de-obra administrativa (capital intelectual) e o nível de rotatividade (turn over) dos empregados.

Fatores Administrativos: este critério refere-se àquelas variáveis relacionadas à estrutura organizacional e ao estilo de gestão da empresa em estudo. Questões como responsabilidade social, gerenciamento ambiental e utilização de um sistema de informações gerenciais foram alguns dos subfatores analisados e considerados no custo de capital da empresa.

\section{. Relacionar os subcritérios com as alternativas}

Esta é a etapa mais importante de todo o processo, pois envolve associar cada subfator a um nível de risco específico. Para obtenção dos parâmetros, foi aplicado inicialmente um questionário na empresa. Tal instrumento orientou as entrevistas realizadas com os gestores das áreas comercial, financeira, administrativa e operacional, bem como junto aos diretores da referida empresa. A partir de uma categorização do tipo ordinal, o questionário captou a intensidade com que os subfatores de risco eram percebidos na empresa. As respostas foram, então, 
ajustadas por meio de outros dados coletados na entrevista, mediante perguntas abertas associadas às diversas variáveis, tais como:

- dada a variação das vendas da empresa em X\%, qual dos 5 prêmios de risco (do risco muito baixo $-6 \%$ ao risco muito alto - 30\%) será o mais apropriado?

. até que ponto a falta de responsabilidade social afeta o risco do negócio?

Neste ponto, o modelo sofreu alguns ajustes, porquanto, ao invés de se utilizar matriz de comparação paritária para a escolha de cada alternativa (prêmio de risco), optou-se por simplificar o processo por meio da opção direta de cada intervalo de prêmio de risco, tal como sugerem Cotner e Fletcher (1999).

. Definir a importância relativa (peso) dos fatores e subfatores

Esta etapa consistiu em analisar e determinar a importância relativa de cada fator e subfator em relação à formação do custo de capital da empresa, por meio do sistema de matriz de comparação paritária.

Quando o modelo possui subfatores, como no presente caso, o processo é realizado em dois estágios: primeiramente a técnica é aplicada para determinar a importância relativa de cada fator relacionado ao custo de capital; a seguir, a importância relativa de cada subfator é calculada e associada ao fator correspondente por meio da matriz de comparação paritária.

- Cálculo do custo de capital

A última etapa reuniu os valores obtidos parcialmente e consistiu em agrupar os pesos e os níveis de risco relacionados a cada subcritério para se chegar a um prêmio global.

\section{Análise dos Resultados}

Neste estudo empírico, os valores e parâmetros obtidos referem-se a uma indústria de médio porte do setor metal mecânico do Estado do Ceará. A companhia, que é sociedade anônima de capital fechado, iniciou suas atividades em 1997 e pertence a um grupo multinacional japonês. É a $110^{\mathrm{a}}$ no ranking das maiores empresas cearenses e é a $4^{a}$ dentro do setor metalúrgico. De modo geral, podese dizer que é uma empresa sólida, bem gerenciada, com boas perspectivas de crescimento. No entanto, a partir da análise quantitativa e qualitativa de seus dados, foi possível estabelecer fundamentos consistentes para demonstrar a viabilidade do modelo proposto. 
A aplicação do método AHP neste processo requereu, em primeiro lugar, identificar as alternativas (prêmio de risco), apresentadas abaixo.

\section{Tabela 1: Categorias de Risco}

\begin{tabular}{c|c}
\hline Nível de Risco & $\begin{array}{c}\text { Prêmio de } \\
\text { Risco }\end{array}$ \\
\hline Muito baixo & $6 \%$ \\
\hline Baixo & $9 \%$ \\
\hline Médio & $14 \%$ \\
\hline Alto & $21 \%$ \\
\hline Muito alto & $30 \%$ \\
\hline
\end{tabular}

Fonte: pesquisa própria.

Em um segundo momento, os principais fatores (e subfatores) de risco da empresa foram identificados e analisados, a partir das características próprias do negócio, ajustados mediante o levantamento de outras informações qualitativas, observando-se, ao mesmo tempo, as condições macroeconômicas e setoriais. O quadro seguinte apresenta as variáveis apontadas.

\section{Quadro 4: Fatores e Subfatores de Risco}

\begin{tabular}{|l|l|}
\hline \multicolumn{1}{|c|}{ Fatores Sistemáticos } & \multicolumn{1}{c|}{ Fatores Estratégicos } \\
\hline Condições político-econômicas & Participação no mercado \\
\hline Taxa de crescimento do setor & Produtos \\
\hline Incentivos governamentais & Estabelecimento de planos estratégicos \\
\hline \multicolumn{1}{|c|}{ Fatores Financeiros } & Domínio do marketing \\
\hline Nível de endividamento & Clientela \\
\hline Liquidez & Fornecedores \\
\hline Variação nas vendas e lucros & \multicolumn{1}{c|}{ Fatores de Recursos Humanos } \\
\hline Capacidade de pagamento/geração de caixa & Investimento em R.H \\
\hline Retorno do investimento & Capital intelectual/ mão-de-obra especializada \\
\hline \multicolumn{1}{|c|}{ Fatores Administrativos } & Turn over empregados \\
\hline Estilo de gestão & Política de R.H. \\
\hline Responsabilidade social & \multicolumn{1}{c|}{ Fatores Operacionais } \\
\hline Sistemas de apoio e informações gerenciais & Custos operacionais \\
\hline Gerenciamento ambiental & Estágio tecnológico \\
\hline Estrutura organizacional & Capacidade produtiva \\
\hline & Qualidade e gerenciamento da produção \\
\hline
\end{tabular}

Fonte: pesquisa própria.

Posteriormente, os subfatores foram relacionados às alternativas (os resultados finais encontram-se na Tabela 4), mediante a aplicação de questionário, em conformidade com outras informações mercadológicas. 
O próximo passo do processo foi estabelecer a importância relativa de cada fator de risco em relação ao custo de capital da empresa. O procedimento consistiu em comparar aos pares os fatores apontados anteriormente, por meio do sistema de matriz, utilizando-se a escala de Saaty (vide Quadro 3). Os valores apresentados correspondem à escala de valores de comparações paritárias, proposta por Saaty (1991), e fazem parte da técnica da análise hierárquica em que se procura estabelecer o grau de importância de uma variável (fator) em relação a outra. Os resultados foram os seguintes:

\begin{tabular}{|l|c|c|c|c|c|c|}
\hline FATORES & SISTEMÁTICOS & FINANCEIROS & OPERACIONAIS & ESTRATÉGICOS & R.H & ADMINISTRATIVOS \\
\hline SISTEMÁTICOS & 1 & $1 / 5$ & $1 / 7$ & $1 / 4$ & $1 / 3$ & $1 / 5$ \\
\hline FINANCEIROS & 5 & 1 & 2 & 3 & 4 & 6 \\
\hline OPERACIONAIS & 7 & $1 / 2$ & 1 & 5 & 6 & 4 \\
\hline ESTRATÉGICOS & 4 & $1 / 3$ & $1 / 5$ & 1 & 4 & 3 \\
\hline R.H & 3 & $1 / 4$ & $1 / 6$ & $1 / 4$ & 1 & $1 / 2$ \\
\hline ADMINISTRATIVO & 5 & $1 / 6$ & $1 / 4$ & $1 / 3$ & 2 & 1 \\
\hline
\end{tabular}

Observando a matriz anterior, nota-se que os fatores sistemáticos foram os que, numericamente, apresentaram menor importância em relação aos outros. O peso de cada um deles pôde ser constatado, a partir do processo de normalização da matriz, apresentado a seguir.

\begin{tabular}{|l|c|c|c|c|c|c|}
\hline FATORES & SISTEMÁTICOS & FINANCEIROS & OPERACIONAIS & ESTRATÉGICOS & R.H & ADMINISTRATIVOS \\
\hline SISTEMÁTICOS & 0,0400 & 0,0816 & 0,0380 & 0,0254 & 0,0192 & 0,0136 \\
\hline FINANCEIROS & 0,2000 & 0,4082 & 0,5320 & 0,3051 & 0,2308 & 0,4082 \\
\hline OPERACIONAIS & 0,2800 & 0,2041 & 0,2660 & 0,5085 & 0,3462 & 0,2721 \\
\hline ESTRATÉGICOS & 0,1600 & 0,1361 & 0,0532 & 0,1017 & 0,2308 & 0,2041 \\
\hline R.H & 0,1200 & 0,1020 & 0,0443 & 0,0254 & 0,0577 & 0,0340 \\
\hline ADMINISTRATIVOS & 0,2000 & 0,0680 & 0,0665 & 0,0339 & 0,1154 & 0,0680 \\
\hline
\end{tabular}

Tal processo consiste em proporcionalizar as medidas encontradas na matriz anterior, de maneira a fornecer o escalonamento do seu grau de importância. Este procedimento permitiu definir a importância relativa de cada fator, que ficou determinada como se apresenta na tabela abaixo.

Tabela 2: Importância Relativa dos Fatores de Risco

\begin{tabular}{l|r}
\hline \multicolumn{1}{c|}{ FATORES } & \multicolumn{1}{c}{ PESO } \\
\hline SISTEMÁTICOS & $3,63 \%$ \\
\hline FINANCEIROS & $34,74 \%$ \\
\hline OPERACIONAIS & $31,28 \%$ \\
\hline ESTRATÉGICOS & $14,76 \%$ \\
\hline R.H & $6,39 \%$ \\
\hline ADMINISTRATIVOS & $9,20 \%$ \\
\hline
\end{tabular}

Fonte: pesquisa própria. 
Mediante o modelo AHP, foi possível determinar a importância relativa de cada fator em relação ao custo de capital de uma empresa em forma de hierarquia (ou grau de prioridade). Assim, de acordo com os dados acima, os fatores financeiros (34,74\%) e operacionais $(31,28 \%)$ foram os mais representativos, seguidos dos estratégicos (14,76\%), administrativos (9,20\%), de R.H (6,39\%) e, por último, os sistemáticos (3,63\%). Portanto observe-se que, na formação do custo de capital, os dois primeiros estão contribuindo com maior expressividade relativa.

Para calcular o peso de cada subfator, foram realizados os mesmos procedimentos (comparação aos pares e normalização da matriz). A seguir, são apresentados resumidamente os resultados obtidos.

\section{Tabela 3: Importância Relativa dos Subfatores de Risco}

\begin{tabular}{l|c|l|c}
\hline \multicolumn{1}{c|}{ Fatores Sistemáticos } & Peso & \multicolumn{1}{c}{ Fatores Estratégicos } & Peso \\
\hline Condições político-econômicas & $20 \%$ & Participação no Mercado & $14 \%$ \\
\hline Taxa de crescimento do setor & $12 \%$ & Produtos & $38 \%$ \\
\hline Incentivos governamentais & $68 \%$ & Estabelecimento de planos estratégicos & $26 \%$ \\
\hline \multicolumn{1}{c|}{ Fatores Financeiros } & & Domínio de marketing & $5 \%$ \\
\hline Nível de endividamento & $17 \%$ & Clientela & $11 \%$ \\
\hline Liquidez & $20 \%$ & Fornecedores & $6 \%$ \\
\hline Variação nas vendas e lucros & $11 \%$ & \multicolumn{1}{|c}{ Fatores de Recursos Humanos } & \\
\hline Capacidade do pagamento/geração do caixa & $47 \%$ & Investimento em RH & $14 \%$ \\
\hline Retorno do investimento & $5 \%$ & $\begin{array}{l}\text { Capital intelectual/ mão-de-obra } \\
\text { especializada }\end{array}$ & $52 \%$ \\
\hline \multicolumn{1}{c|}{ Fatores Administrativos } & & Turn over empregados & $8 \%$ \\
\hline Estilo de gestão & $5 \%$ & Política de R.H. & $26 \%$ \\
\hline Responsabilidade social & $11 \%$ & & \multicolumn{1}{c}{ Fatores Operacionais } \\
\hline Sistema de apoio e informações gerenciais & $37 \%$ & Custos operacionais & $51 \%$ \\
\hline Gerenciamento ambiental & $29 \%$ & Estágio tecnológico & $28 \%$ \\
\hline Estrutura organizacional & $18 \%$ & Capacidade produtiva & $15 \%$ \\
\hline
\end{tabular}

Fonte: pesquisa própria.

Desta forma, estimou-se a importância relativa de cada subcritério na formação do prêmio de risco da empresa. A tabela seguinte apresenta os resultados globais, obtidos mediante a ponderação dos fatores e subfatores em relação ao seu nível de risco. 


\section{Tabela 4: Resultado Final do Cálculo do Prêmio de Risco}

\begin{tabular}{|c|c|c|c|c|c|}
\hline VARIÁVEIS & PESO R & LATIVO & NÍVEL DE RISCO & $\%$ & PRÊMIO DE RISCO \\
\hline FATORES SISTEMÁTICOS & \multicolumn{2}{|c|}{$3,63 \%$} & & & $0,28 \%$ \\
\hline Condições político-econômicas & $20 \%$ & $0,73 \%$ & médio & $14 \%$ & $0,10 \%$ \\
\hline Taxa de crescimento do setor & $12 \%$ & $0,43 \%$ & muito baixo & $6 \%$ & $0,03 \%$ \\
\hline Incentivos Governamentais & $68 \%$ & $2,47 \%$ & muito baixo & $6 \%$ & $0.15 \%$ \\
\hline FATORES OPERACIONAIS & \multicolumn{2}{|c|}{$31,28 \%$} & & & $3,36 \%$ \\
\hline Custos operacionais & $51 \%$ & $16.08 \%$ & médio & $14 \%$ & $2.25 \%$ \\
\hline Estágio tecnológico & $28 \%$ & $8,69 \%$ & muito baixo & $6 \%$ & $0.52 \%$ \\
\hline Capacidade produtiva & $15 \%$ & $4.73 \%$ & baixo & $9 \%$ & $0.43 \%$ \\
\hline Qualidade e gerenciamento da produção & $6 \%$ & $1,78 \%$ & baixo & $9 \%$ & $0,16 \%$ \\
\hline \multicolumn{3}{|l|}{ FATORES FINANCEIROS } & & & $3,41 \%$ \\
\hline Liquidez & $20 \%$ & $7,08 \%$ & baixo & $9 \%$ & $0,64 \%$ \\
\hline Nível de endividamento & $17 \%$ & $5.73 \%$ & medio & $14 \%$ & $0.80 \%$ \\
\hline Variação nas vendas e lucros & $11 \%$ & $3,80 \%$ & baixo & $9 \%$ & $0,34 \%$ \\
\hline Capacidade de pagamento & $48 \%$ & $16,54 \%$ & baixo & $9 \%$ & $1,49 \%$ \\
\hline Retorno do investimento & $5 \%$ & $1,58 \%$ & baixo & $9 \%$ & $0,14 \%$ \\
\hline FATORES ESTRATÉGICOS & \multicolumn{2}{|c|}{$14,76 \%$} & & & $1,98 \%$ \\
\hline Participação no mercado & $14 \%$ & $2,06 \%$ & baixo & $9 \%$ & $0,19 \%$ \\
\hline Produtos & $38 \%$ & $5,68 \%$ & alto & $21 \%$ & $1,19 \%$ \\
\hline Planos estratégicos & $26 \%$ & $3,77 \%$ & muito baixo & $6 \%$ & $0.23 \%$ \\
\hline Domínio do marketing & $5 \%$ & $0,70 \%$ & médio & $14 \%$ & $0.10 \%$ \\
\hline Clientela & $11 \%$ & $1.68 \%$ & baixo & $9 \%$ & $0.15 \%$ \\
\hline Fornecedores & $6 \%$ & $0,87 \%$ & médio & $14 \%$ & $0.12 \%$ \\
\hline FATORES DE R.H. & \multicolumn{2}{|c|}{$6,39 \%$} & & & $0.73 \%$ \\
\hline Investimento em R.H & $14 \%$ & $0,87 \%$ & baixo & $9 \%$ & $0.08 \%$ \\
\hline Capital intelectual & $52 \%$ & $3.33 \%$ & médio & $14 \%$ & $0.47 \%$ \\
\hline Turn over dos empregados & $8 \%$ & $0,50 \%$ & muito baixo & $6 \%$ & $0,03 \%$ \\
\hline Política de R.H & $26 \%$ & $1,69 \%$ & baixo & $9 \%$ & $0,15 \%$ \\
\hline \multicolumn{3}{|l|}{ FATORES ADMINISTRATIVOS } & & & $1,18 \%$ \\
\hline Estilo de gestão & $5 \%$ & $0,42 \%$ & médio & $14 \%$ & $0,06 \%$ \\
\hline Responsabilidade social & $11 \%$ & $0,98 \%$ & alto & $21 \%$ & $0,21 \%$ \\
\hline Sistemas gerenciais & $37 \%$ & $3,45 \%$ & baixo & $9 \%$ & $0,31 \%$ \\
\hline Gerenciamento ambiental & $29 \%$ & $2,69 \%$ & médio & $14 \%$ & $0,38 \%$ \\
\hline Estrutura organizacional & $18 \%$ & $1,66 \%$ & médio & $14 \%$ & $0.23 \%$ \\
\hline RESULTADO FINAL & & & & & $10.93 \%$ \\
\hline
\end{tabular}

Fonte: pesquisa própria.

A última célula desta tabela apresenta o prêmio de risco que ficou estimado em 10,93\%, composto pelo somatório de todas as variáveis apontadas neste estudo.

Por meio deste processo, pode-se perceber ainda quanto cada fator representa no prêmio total estabelecido, podendo até mesmo ser analisado hierarquicamente, como mostram os dados a seguir.

Tabela 5: Contribuição Hierárquica dos Fatores de Risco

\begin{tabular}{l|r}
\hline FATORES FINANCEIROS & $3,41 \%$ \\
\hline FATORES OPERACIONAIS & $3,36 \%$ \\
\hline FATORES ESTRATÉGICOS & $1,98 \%$ \\
\hline FATORES ADMINISTRATIVOS & $1,18 \%$ \\
\hline FATORES DE R.H. & $0,73 \%$ \\
\hline FATORES SISTEMÁTICOS & $0,28 \%$ \\
\hline SOMATÓRIO & $10,93 \%$ \\
\hline
\end{tabular}

Fonte: pesquisa própria. 
Pela tabela anterior, constata-se que, na formação do prêmio de risco estimado em $10,93 \%$, os fatores financeiros participam com maior representatividade, apresentando um percentual de 3,41\%, seguido dos operacionais com 3,36\%. Já os sistemáticos contribuem com apenas 0,28\%. Pode-se afirmar que, para o presente caso, o risco maior da empresa está atrelado às suas atuais condições financeiras e operacionais.

Analisando hierarquicamente cada variável (subfatores), a conclusão foi a que se apresenta na tabela abaixo.

\section{Tabela 6: Contribuição Hierárquica dos Subfatores de Risco}

\begin{tabular}{|c|c|}
\hline Custos Operacionais & $2,25 \%$ \\
\hline Capacidade de Pagamento & $1,49 \%$ \\
\hline Produtos & $1,19 \%$ \\
\hline Nível de Endividamento & $0,80 \%$ \\
\hline Liquidez & $0,64 \%$ \\
\hline Estágio Tecnológico & $0,52 \%$ \\
\hline Capital Intelectual & $0,47 \%$ \\
\hline Capacidade Produtiva & $0,43 \%$ \\
\hline Gerenciamento Ambiental & $0,38 \%$ \\
\hline Variacão nas Vendas e Lucros & $0,34 \%$ \\
\hline Sistemas Gerenciais & $0,31 \%$ \\
\hline Estrutura Organizacional & $0,23 \%$ \\
\hline Planos Estratégicos & $0,23 \%$ \\
\hline Responsabilidade Social & $0,21 \%$ \\
\hline Participação no Mercado & $0,19 \%$ \\
\hline Qualidade e Gerenciamento da Produção & $0,16 \%$ \\
\hline Política de R.H & $0,15 \%$ \\
\hline Clientela & $0,15 \%$ \\
\hline Incentivos Governamentais & $0,15 \%$ \\
\hline Retorno do Investimento & $0,14 \%$ \\
\hline Fornecedores & $0,12 \%$ \\
\hline Condiç̃os Político-Econômicas & $0,10 \%$ \\
\hline Domínio do Marketing & $0,10 \%$ \\
\hline Investimento em R.H & $0,08 \%$ \\
\hline Estilo de Gestão & $0,06 \%$ \\
\hline Turn over dos Empregados & $0,03 \%$ \\
\hline Taxa de Crescimento do Setor & $0,03 \%$ \\
\hline PRÊMIO TOTAL & $10,93 \%$ \\
\hline
\end{tabular}

Fonte: pesquisa própria. 
De acordo com a Tabela 6, a variável custos operacionais, com 2,25\%, foi a que mais contribuiu na formação do prêmio de risco, seguida da capacidade de pagamento $(1,49 \%)$ e produtos $(1,19 \%)$. Observe-se que os dois primeiros fazem parte dos fatores operacionais e financeiros, enquanto a variável produtos se relaciona aos fatores estratégicos. Por sua vez, a variável taxa de crescimento do setor (fator de risco sistemático) representou apenas 0,03\% do total de 10,93\%.

Uma vez determinado o prêmio de risco, foi possível calcular o custo de capital próprio que, somado a uma taxa de livre de risco - TJLP (10\%), resultou em um percentual de $20,93 \%$.

\section{Conclusão}

Os estudos empíricos e teóricos desenvolvidos ultimamente enfatizam modelos voltados a grandes empresas de capital aberto, corroborando o seguinte: as companhias que não operam em bolsa necessitam de um suporte científico mais aprofundado.

Neste estudo, procurou-se mostrar uma alternativa para obtenção do custo de capital próprio, contribuindo para o desenvolvimento do tema, mediante o emprego de abordagens não tradicionais. A aplicação desta metodologia, de caráter interdisciplinar, deu-se por meio de suportes da Teoria de Decisão Multicritério, especialmente pelo Método de Análise Hierárquica (AHP).

O AHP possibilitou incluir as várias dimensões do risco na taxa de desconto, incorporando simultaneamente variáveis qualitativas e quantitativas no processo. O método permitiu, ao mesmo tempo, apontar, ordenadamente, como os diversos fatores (e subfatores) estão contribuindo na formação do prêmio de risco da empresa, fato este não verificado em outras técnicas de análise.

Assim, de um prêmio total de 10,93\%, os fatores financeiros representaram $3,41 \%$; os operacionais $3,36 \%$; os estratégicos $1,98 \%$; os administrativos $1,18 \%$; os relacionados aos recursos humanos $0,73 \%$; e os sistemáticos $0,28 \%$. A partir destes dados, pode-se concluir que o risco maior da empresa analisada está vinculado a seus aspectos operacionais e financeiros.

O detalhamento por subfatores propiciou ainda observar hierarquicamente que a variável correspondente aos custos operacionais é a que tem causado maior impacto no total do prêmio estimado, apresentando um percentual de 2,25\%, contrariamente à taxa de crescimento do setor, que foi de apenas 0,03\%. Estas 
informações denotam que, para diminuir seu nível de risco, a empresa deve mobilizar-se, principalmente, em busca de uma gestão eficaz de seus custos.

Por outro lado, um prêmio de 10,93\% sugere que, de maneira geral, a indústria em estudo apresenta nível relativamente baixo de risco, parâmetro este compatível, quando suas características foram avaliadas minuciosamente.

Ademais, o resultado final de 20,93\% se mostrou coerente com os achados de Martins (1998), uma vez que, para o referido autor, as taxas praticadas nos últimos anos, envolvendo empresas de capital fechado, têm ficado na faixa entre $14 \%$ e 20\%, próximas, portanto, ao custo do patrimônio aqui obtido.

Logo, diante das constatações anteriores, pôde-se verificar a viabilidade do modelo proposto e a sua relevância no processo de avaliação mormente daquelas de capital fechado. A despeito de ter sido aqui utilizado o método AHP em dimensão determinística, a princípio nada parece impedir a sua extensão de forma probabilística, mediante o estabelecimento de intervalos de confiança para os resultados. Isto poderia ser viabilizado, entre outras formas, pelo uso da simulação digital aplicada aos valores estimados.

Várias são as vantagens de se utilizar o método AHP na estimativa do prêmio de risco da empresa. Com este dado em mão, na prática, o administrador pode perceber mais facilmente as áreas problemáticas de seu negócio, concentrandose naquelas responsáveis pelo aumento do risco operacional e financeiro. Salientase ainda que, pela disposição hierárquica das variáveis (subfatores) apontadas, o decisor pode ter uma perspectiva mais específica do problema, favorecendo a análise e, conseqüentemente, a tomada de decisão.

\section{ReferênCIAs Bibliográficas}

ANNIN, M. E.;

FALASCHETTI, A. D.

Is there still a size premium? CPA

Experts, 1998a.

Equity risk premium still produces debate. Valuation Strategies, v. 44, p. 17-19, Jan./Feb. 1998 b.

BANZ, R.

The relationship between return and market value of common stocks. Journal of Financial Economics, n. 9, p. 3-18, 1981.

BREALEY, R. A.; MYERS, S. C.

Princípios de finanças empresariais. 5. ed. Portugal: McGraw-Hill, 1998. 
BRUNI, A. L.

Mercados eficientes, CAPM e anomalias na BOVESPA (19881996). II SEMEAD, 1998.

CASAROTTO FILHO, N.;

KOPITTKE, B. H.

Análise de investimentos. 9. ed. São Paulo: Atlas, 2000.

COSTA JR., N. C. A.;

LEAL, R. P. C.;

LEMGRUBER, E. F.

Mercado de capitais: análise empírica no Brasil. São Paulo: Atlas, 2000.

COTNER, J.;

FLETCHER, H.

Computing the cost of capital for privately held firms. 1999 Disponível em: < http:// www.sbcer.uca.edu> Acesso em: 6 abr. 2001.

DAMODARAN, A.

A face oculta da avaliação. São Paulo: Makron Books, 2002.

EDWARD, V.

A conceptual framework for practical risk measurement in small business. Journal of Small Business Management, July 1992.

FAMA, E. F.;

FRENCH, K. R.

The cross-section of expected stock returns. Journal of Finance, v. 47, p. 427-465, 1992.
Common risk factors in the returns on stocks and bonds. Journal of Financial Economics, v. 33, p. 356, 1993.

GOODWIN, P.;

WRIGHT, G.

Decision analysis for management judgment. 2. ed. London: Wiley, 2000.

GRABOWSKI, R; KING, D.

New evidence on size effects and rates of return. Business Valuation Review, p. 103-114, Sept. 1996.

New evidence on equity returns and company risk. Business Valuation Review, p. 112-130, Sept. 1999.

HAMILTON CAPITAL PARTNER. A practical guide for preliminary valuations in mergers and acquisition arena. Disponível em: <http: www.hamiltonllc.com/ pract_val_guide.htm> Acesso em: 5 maio 2001.

HOWITT, I.

A. Valuing closely held stock. CPA Journal Online, Sept. 1993.

IBBOTSON ASSOCIATES.

Stocks, bonds, bills \& inflation: valuation edition 1997 yearbook. Chicago, 1997. 
IBBOTSON, R. G.;

KAPLAN, P. D.;

PETERSON, J. D.

Estimates of small stocks betas are much too low. Journal of Portfolio Management, Summer 1997.

LIPPITT, J. W.;

MASTRACCHIO JR., N.

Developing capitalization rates for valuing a business. CPA Journal On Line, Nov. 1995.

MANNING, L. R.

What's it worth? A guide to valuing a small business. Oregon: The Oasis Press, 2000.

MARTELANC, R. Passos para avaliação de uma empresa de pequeno porte pelo método do valor presente do fluxo de caixa constante ( $2^{\mathrm{a}}$ e última parte). Temática Contábil, boletim 46/98, p. 1-6, 1998.

MARTINS, E. Avaliando a empresa (I). Temática Contábil, boletim 10/ 98, p. 1-6, 1998.

MASCAREÑAS, J.

El coste del capital. Universidad Complutense de Madrid, 2000.

PORTER, M. E.

A estratégia competitiva das nações. Rio de Janeiro: Campus, 1986.
PRATT, S. P.

Cost of capital: estimation and applications. New York: John Wiley \& Sons, 1998a.

Valuing small business and professional practices. 3. ed. New York: McGraw-Hill, 1998b.

PRATT, S. P.;

REILLY, R. F.;

SCHWEIHS, R. P.

Valuing a business: the analysis and appraisal of closely held companies. 4. ed. [S.l.]: Irwin Library, 2000.

REILLY, R. F.;

SCHWEIHS, R. P.

Handbook of advanced business valuation. New York: McGraw-Hill, 2000.

REINGANUM, M.

Misspecification of capital asset pricing: empirical anomalies based on earning yields and market values. Journal of Financial Economics, v. 9, 1981.

RODRIGUES, M. R. A.

O efeito valor, o efeito tamanho e o modelo multifatorial: evidências do caso brasileiro. In: ENCONTRO ANUAL DA ANPAD, 24., 2000, Florianópolis. Anais... Rio de Janeiro: ANPAD, 2000. 1 CD-ROM.

SAATY, T. L.

Método de análise hierárquica. São Paulo: Markron Books, 1991. 
SCHILT, J. H.

A rational approach to capitalization rates for discounting the futures income stream of closely held companies. The Financial Planner, Jan. 1982.

SHIMIZU, T.

Decisão nas organizações. São Paulo: Atlas, 2001.

SWAD, R.

Discount and capitalization rates in business valuations. CPA Journal Online, Oct. 1994.
TULLER, L. W. The small business valuation book. Massachusetts: Adams Media Corporation, 1994.

WEST, T. L.;

JONES, J. D.

Handbook of business valuation. New York: John Wiley \& Sons, 1999.

WINSTON, W. L.;

ALBRIGHT, S. C.

Practical management science.

2. ed. California: Duxbury, 2001. 